\title{
EFFECT OF EUGENOL, NERIDOL AND PIPERINE FEED SUPPLEMENT ON THE THIGH MUSCLE FAT PROFILE OF BROILER CHICKENS
}

\author{
Mária Angelovičová, Michaela Klimentová, Marek Angelovič
}

\begin{abstract}
The purpose of this study was to investigate of the broiler chicken thigh muscle fat profile after feeding a commercial supplement based on eugenol, nerolidol and piperine applied in feeding mixtures. Broiler chickens Ross 308 were reared in a pen equipped with a straw deep litter and placed into 2 groups. One group was designated as control and the second as experimental. Difference between control and experimental groups was in using of feed supplement in experimental feeding mixtures. Experimental supplement is a commercial powder product which was used in an amount of $10 \mathrm{~g}$ per $100 \mathrm{~kg}$ of feeding mixtures. Chickens of body weight of $1800.0 \mathrm{~g}$ were selected from each group, human killed and technologically processed to carcass. Samples were measured according to Fourier Transform Infrared Spectroscopy (FTIR) using the Nicolet 6700 instrument. Infrared area near middle was chosen for determining fat and fatty acids. Mean fat content was found slightly higher value $1.53 \mathrm{~g} .100 \mathrm{~g}^{-1}$ in experimental group opposite $1.49 \mathrm{~g}^{1} 100 \mathrm{~g}^{-1}$ in control group showing no statistically significant difference $(p>0.05)$. Ratio among saturated fatty acids (SFAs), monounsaturated fatty acids (MUFAs) and polyunsaturated fatty acids (PUFAs) was 4.24:5.89:1 in experimental group and 3.75:5.13:1 in control group. Omega-3 PUFAs content was reached $0.54 \%$ in experimental group and $0.58 \%$ in control group showing no statistically significant $(p>0.05)$. Near-perfect correlation was found between total PUFAs and omega-6 PUFAs as well in the experimental group and control group showing linear, positive and statistically significant relation $(p<0.01, p<0.001)$. Ratio between omega-3 and omega-6 PUFAs was statistically significant $(p<0.05)$ closer in experimental group 1:14.65 opposite ratio 1:16.78 in control group. Conclusion: comparable fat profile in the thigh muscle was achieved, showing no statistically significant difference $(p>0.05)$, in addition to the correlation between total PUFAs and omega-6 PUFAs, which was statistically significant in control $(p<0.001)$ and experimental groups $(p<0.01)$, and statistically significant $(p$ $<0.05$ ) closer relation between omega-3 and omega-6 PUFAs in experimental group.
\end{abstract}

Keywords: feed supplement of eugenol; neridol and piperine; broiler chicken; thigh muscle; fat; fatty acid

\section{INTRODUCTION}

We have followed this study for ongoing research at the Slovak University of Agriculture in Nitra, published by Tkáčová et al. (2015), which states, on the basis of the oxidative stability results of chicken meat, that the natural feed component has its justification. This issue requires however, further research. Natural-based products such as, for example, clams, oregano, mint, thyme and cinnamon have been used for many centuries as food preservatives and as medicinal plants, mainly because of their antioxidant and antimicrobial effects. At present, many studies confirm the wide range of properties of these natural resources for public health. Since the ban on the use of feed antibiotics has been the subject of many scientific teams' research. Of these plant products, the aroma of Syzygium aromaticum attracted attention mainly because of its strong antioxidant and antimicrobial activity (Mbaveng and Kuete, 2017). Kardum and Glibetic (2018) examined natural resources richest on polyphenols. The results show that the spice is a food type with a higher content of polyphenols, followed by fruit, seeds and vegetables. The primacy of the spice is fragrant Syzygium aromaticum, which has a higher content of polyphenols and antioxidants. Essential oil of Syzygium aromaticum could also be used to influence lipid peroxidation and enzyme activities of catalase, glutathione-S-transferase, peroxidase, polyphenol oxidase and superoxide dismutase (Afify et al., 2012).

\section{Literature review conclusion on Syzygium aromaticum biological effects}

On the basis of literary knowledge, Syzygium aromaticum is a very interesting plant with enormous potential to use as a food preservative as a rich source of antioxidant compounds. It is proved that its biological effects indicate the development of human and animal drugs and further use in agriculture. This information confirms the use of this plant over the centuries. 
Lavender medicine (Lavandula augustifolia, L. officinalis, L. vera) contains essential oil, anthocyanins, phytosterols, sugars, minerals, kumaric acid, glycolic acid, valoric acid, ursolic acid, herniarin, coumarin and tallow (Dănilă et al., 2018).

Essential oils from Lavender plants show a wide range of biological activities. The essential oil of Lavandula dentata has an inhibitory effect on the growth of bacteria including Salmonella, Enterobacter, Klebsiella, Escherichia coli, Salmonella aureus and Listeria monocytogenes. On the other hand, essential oil of Syzygium bipinnata has antibacterial properties against Escherichia coli, Pseudomonas aeruginosa, S. aureus and Bacillus subtilis and antifungal properties against Aspergillus niger, Penicillium notatum, Candida albicans at concentrations from 0.5 to $2.0 \mu \mathrm{g} . \mathrm{mL}^{-1}$ for bacteria and from 2.0 to $4.0 \mu \mathrm{g} \cdot \mathrm{mL}^{-1}$ for fungi (Hanamanthagouda et al., 2010). Essential oils have antioxidant properties, which protect the cells against the harmful effects of free radicals. Lavender medical essential oil has proven antioxidant activity (Blažeković et al., 2018). Hui et al. (2010) demonstrated the inhibitory effect of this essential oil on fat oxidation and lipid peroxidation in the linoleic acid model system. Angelovič et al. (2015) state that the mechanisms of oxidative degradation can be autoxidation in presence of atmospheric oxygen. Chia-Wen et al. (2009) used organic chemical compound 2.2-diphenyl-1picrylhydrazyl (DPPH) to study the antioxidant properties of lavender essential oil and especially its ability to inactivate free radicals. The value of $15.18 \pm 0.009 \%$ at a concentration of 5 g. $\mathrm{L}^{-1}$ indicated properties comparable to essential oils of lime and marjoram. Viuda-Martos et al. (2011) reported a significantly lower ability of essential oil to deactivate free radicals at a similar concentration $(4.11 \%)$. Studies testing the ability of this essential oil to reduce $50 \%$ of DPPH residues resulted in different results ranging from $289 \mu \mathrm{g} \cdot \mathrm{mL}^{-1}$ to $48.7 \mathrm{mg} \cdot \mathrm{mL}^{-1}$. According to Pereira et al. (2018) some essential oils such as linalool and terpineol, have an effect on the central nervous system, weaken the physical activity of humans and animals, reduce anxiety, and ease sleep. In a study of brain waves, it turned out that 40 healthy adults had increased beta wave activity, and in mathematical tests they were more successful just after inhalation of essential oil lavender medical. On the other hand, it is reported that patients felt relaxed and showed a positive attitude towards life, but was accompanied by drowsiness (Lee et al., 2017).

\section{Literature review conclusion on Lavandula augustifolia biological effects}

Experiences from scientific and scientific literature suggest that L. angustifolia and its secondary metabolites have a very good biological activity with many uses. Research has confirmed that lavender medicine grown in different regional regions is a valuable plant source with chemical and biological properties applicable in many areas of agriculture, medicine, etc. Current modern medicine should pay attention to the synergistic effect of secondary metabolites of plants and synthetic drugs as they can help solve many problems including microbial resistance to synthetic antibiotics.
Piper nigrum L., the genus Piperaceae, is one of the most widely used spices in the world, known for its pungent component piperine. Piperine is the major bioactive compound of Piper nigrum and Piper longum, which are reported to have immunomodulatory, anticarcinogenic, antiasthmatic, stimulatory, hepatoprotective, anti-inflammatory, anti-viral and antimicrobial effects (Abdulazeez et al., 2016). The method of storing and processing spices is particularly important because piperine is a key active compound and its effectiveness is easily lost due to exposure to heat, for example, in a variety of domestic culinary treatments. Piperine and its isomers pass light-induced isomerisation to isopiperine, chavidine and isochavine. Isomerisation increases with light intensity and exposure time. Chavicin slowly changes to piperine during storage, leading to a loss of pungency. Piperine inhibits many enzyme biotransformation drug responses, which is an important aspect for the metabolic activation of carcinogens and energy production of mitochondria (Ezawa et al., 2017). Further studies confirm that piperine causes specific effects related to its concentration on mitochondrial bioenergy and energy metabolism enzymes (Gorgani et al., 2017). Mgbeahuruike et al. (2017) they concluded that piperine significantly increased pancreatic lipase activity and stimulated pancreatic amylase, trypsin and chymotrypsin. Positive effects on pancreatic digestive enzymes developed by piperine consumed in the diet could be a contributing factor to the well-known digestive stimulating effect of black pepper. The bioavailability and bioactivity of many drugs effectively potentiate piperine. Piperine has the ability to inhibit several enzyme-mediated pathways and biotransformation reactions (Mhaske, Sreedharan and Mahadik, 2018).

\section{Literature review conclusion on Pepper nigrum $\mathrm{L}$. biological effects}

Black pepper is a rich source of many biologically active ingredients, such as monoterpenes, sesquiterphenes and other volatile compounds. Various health benefits of black pepper and black long spice have been confirmed by cell, animal and human tests. It has been found that it has many beneficial therapeutic applications. It is used as an immunomodulator, stimulant, hepato-protective, antiinflammatory, anti-carcinogenic, contraceptive, fungicidal, antibacterial and anti-asthmatic material. It has also been found to cause increased bioavailability of nutrients from food, drugs, anti-carcinogenic and phytochemical substances, and stimulates the effect on enzymes metabolizing the drug. It accelerates metabolism and lipid peroxidation. Modern science has demonstrated the molecular basis of the pharmacological properties of black pepper and black long spice against human disease, and some clinical studies have demonstrated the safety and efficacy of the spice in humans.

Based on the above-mentioned issue, the aim of our work was experimental investigation of broiler chicken thigh muscle fat profile after feeding a commercial supplement based on eugenol, nerolidol and piperine applied in feeding mixtures. 


\section{Scientific hypothesis}

Improving the fat profile of broiler chicken thigh muscles after feeding feed mixtures with the supplement of eugenol, nerolidol and piperine.

\section{MATERIAL AND METHODOLOGY}

Experiment was carried out at Poultry farm Zámostie, Slovakia. Broilers chickens were reared in a pen equipped with a straw deep litter. Broiler chickens Ross 308 were placed into 2 groups, each in 50 pcs. One group was designated as control and the second as experimental. The chickens in the pen had a permanent access to water, to the feed and enough place to move. They have secured welfare in accordance with Council Directive 2007/43/EC. Experimental period was 42 days divided into three stages from 1 to 14 days as a starter, from 15 to 35 days grower and from 36 to 42 days as a finisher. Difference between control and experimental groups was in using of feed supplement in experimental feeding mixtures. Experimental supplement is a commercial powder product based on eugenol, nerolidol and piperine which was used in an amount of $10 \mathrm{~g}$ per $100 \mathrm{~kg}$ of feeding mixtures.

\section{Chemical analysis of broiler chickens thigh muscle on fat profile \\ Prepared of based samples for chemical analysis}

Thigh samples were prepared for chemical analysis in accordance with AOAC 983.18. Chickens were slaughtered at 42 day of age. Chickens were selected from each group of body weight $1800.0 \mathrm{~g}$, human killed and technologically processed to carcass. The left thigh was separated from each carcass. Each thigh was boneless and clear of skin. The thigh muscle was milled with a laboratory homogenizer. A $50.0 \mathrm{~g}$ sample was taken for chemical analysis from each homogenized thigh muscle.

\section{Chemical analysis}

Fourier Transform Infrared Spectroscopy (FTIR) was used for chemical analysis of broiler chicken thigh samples. Sample measurement was done using the Nicolet 6700 instrument. Infrared area near middle was chosen for determining fat, saturated fatty acids, polyunsaturated fatty acids, omega- 3 polyunsaturated fatty acids and omega- 6 polyunsaturated fatty acids.

\footnotetext{
Statistical analysis

All statistical analyses were computed using the ANOVA procedures of SAS software (version 9.3, SAS Institute, USA). Mean values $(\bar{x})$, standard deviation $(S D)$ and variation coefficient $\left(c_{v}\right)$ are reported in tables. Statistical significance was calculated using t-test. Differences between the treatments were considered significant at $p \leq 0.05$. The Pearson correlation coefficient $\left(r_{x y}\right)$ was used to test the relation between the two variables.

According to Cohen (1988), the calculated correlation coefficient value $\left(r_{x y}\right)$ is interpreted as follows: $r_{x y}$ over 0.5 is strong dependence, from 0.3 to 0.5 is middle dependence, and from 0.1 to 0.3 is weak dependence, less than 0.1 is trivial (simple) dependence. Correlation, relation between two variables, as near-perfect, is reached
}

in the range of values from 0.9 to 1.0. A very strong correlation is characterized by values ranging from 0.7 to 0.9 . The strength of correlation between two variables was statistically tested at a significance level $p \leq 0.05, p \leq 0.01$ and $p \leq 0.001$.

\section{RESULTS AND DISCUSSION}

\section{Fat content in broiler chicken thigh muscle}

Mean values and statistical analysis for fat content in broiler chicken thigh muscle shows Table 1. Mean fat content in broiler chicken thigh muscle was found slightly higher value 1.53 g. $100 \mathrm{~g}^{-1}$ in experimental group with supplement of eugenol, nerolidol and piperine opposite $1.49 \mathrm{~g}^{1} 100 \mathrm{~g}^{-1}$ in control group. The difference in fat content in broiler chicken thigh muscle was not statistically significant between groups $(p>0.05)$. Based on the statistical evaluation of the results by standard deviation and coefficient of variation it was found that the measured values of the fat content in the broiler thigh muscle was more even in the control group compared to the measured fat content in the broiler chicken thigh muscle after feeding of the feeding mixtures with a supplement of eugenol, piperine and nerolidol $\left(S D=0.33, c_{v}=21.57 \%\right.$ opposite $\left.S D=0.37, c_{\nu}=24.83 \%\right)$. Investigation and control of the total fat intake in the ingested food has its own justification. Total fat intake recommendations are based on evidence that indicates consumption outside of these ranges is associated with a greater intake of energy and saturated fatty acids (fat intake $>35 \%$ ) or greater intake in carbohydrate (fat intake $<20 \%$ ); higher intake of carbohydrate leads to increases in plasma triglyceride and reductions in high-density lipoprotein cholesterol levels (Vannice and Rasmussen, 2014). The structure of each fatty acid differs. Individual fatty acids may have unique and specific impacts on health. The impact of specific fatty acids on disease incidence is difficult to elucidate. Chronic disease develops over many months to several years and is the culmination of many genetic and lifestyle factors. This complexity makes randomized controlled trials of dietary interventions largely impractical. Experimental trials, coupled with observational, epidemiological, and mechanistic studies, provide valuable evidence of the human health effects of dietary fat and specific fatty acids (Mozaffarian, 2008).

\section{Ratio among saturated, monounsaturated and polyunsaturated fatty acids in fat of broiler chicken thigh muscle}

Mean values for ratio among saturated, monounsaturated and polyunsaturated fatty acids in fat of broiler chicken thigh muscle shows Table 2. Ratio among saturated fatty acids, monounsaturated fatty acids and polyunsaturated fatty acids in fat of broiler chicken thigh muscle was 4.24:5.89:1 in experimental group with supplement of eugenol, nerolidol and piperine and 3.75:5.13:1 in control group. Fatty acid composition is a very important component of meat quality and has received considerable interest in view of its implications for human health (De Smet, Raes and Demeyer, 2004). 
It is well known that the higher intake of saturated fatty acids in the human diet increases the risk of the development of coronary heart disease, atherosclerosis and cancer (Mensink and Katan, 1992), whereas monounsaturated fatty acid and polyunsaturated fatty acid, especially omega-3, have a number of associated health benefits (Siriwardhana et al., 2012).

Table 1 Mean values and statistical analysis for fat content in broiler chicken thigh muscle.

\begin{tabular}{llllll}
\hline \multicolumn{1}{c}{ Group } & $\mathbf{n}$ & $\overline{\boldsymbol{x}}, \mathbf{g . 1 0 0 \mathbf { g } ^ { - 1 }}$ & $\boldsymbol{S D}$ & $\boldsymbol{c}_{\boldsymbol{v}}, \boldsymbol{\%}$ & t-test \\
\hline Control & 6 & 1.49 & 0.33 & 21.57 & \\
Experimental with supplement of & 6 & 1.53 & 0.37 & 24.83 & $p>0.05$
\end{tabular}
eugenol, nerolidol and piperine

Note: $\mathrm{n}-$ multiplicity, $\bar{x}-$ mean, $S D$ - standard deviation, $c_{v}$ - coefficient of variation, $p>0.05$ : no statistically significant difference between control and experimental group with supplement of eugenol, nerolidol and piperine.

Table 2 Mean values for ratio among saturated, monounsaturated and polyunsaturated fatty acids in fat of broiler chicken thigh muscle.

\begin{tabular}{lccc}
\hline & & Ratio & \\
\cline { 2 - 4 } & $\begin{array}{c}\text { Saturated } \\
\text { fatty acids }\end{array}$ & $\begin{array}{c}\text { Monounsaturated } \\
\text { fatty acids }\end{array}$ & $\begin{array}{c}\text { Polyunsaturated } \\
\text { fatty acids }\end{array}$ \\
\hline \multicolumn{1}{c}{ Group } & $\mathbf{n = 6}$ & $\mathbf{n = 6}$ & $\mathbf{n = 6}$ \\
\hline $\begin{array}{l}\text { Control } \\
\begin{array}{l}\text { Experimental with supplement of eugenol, nerolidol } \\
\text { and piperine }\end{array}\end{array}$ & 3.75 & 5.13 & 1 \\
\hline
\end{tabular}

Note: $\mathrm{n}$ - multiciplity, ratio values are calculated from the average values of the fatty acid content.

Table 3 Mean values and statistical analysis for share of omega-3 and omega-6 polyunsaturated fatty acids from total fatty acids in fat of broiler chicken thigh muscle.

\begin{tabular}{|c|c|c|c|c|c|}
\hline Group & $\mathbf{n}$ & $\bar{x}, \%$ & $S D$ & $c_{v}, \%$ & t-test \\
\hline \multicolumn{6}{|c|}{ Omega-3 polyunsaturated fatty acids } \\
\hline Control & 6 & 0.58 & 0.07 & 12.07 & \multirow[b]{2}{*}{$p>0.05$} \\
\hline $\begin{array}{l}\text { Experimental with supplement of eugenol, nerolidol and } \\
\text { piperine }\end{array}$ & 6 & 0.54 & 0.03 & 5.55 & \\
\hline \multicolumn{6}{|c|}{ Omega-6 polyunsaturated fatty acids } \\
\hline Control & 6 & 9.73 & 2.28 & 23.43 & \multirow[b]{2}{*}{$p>0.05$} \\
\hline $\begin{array}{l}\text { Experimental with supplement eugenol, nerolidol and } \\
\text { piperine }\end{array}$ & 6 & 7.91 & 1.98 & 25.03 & \\
\hline
\end{tabular}

Note: $\mathrm{n}$ - multiplicity, $\bar{x}-$ mean, $S D$ - standard deviation, $c_{v}$ - coefficient of variation, $p>0.05$ : no statistically significant difference between control and experimental group with supplement of eugenol, nerolidol and piperine.

Table 4 Correlation relation between polyunsaturated, omega-3 and omega-6 polyunsaturated fatty acids in fat of broiler chicken thigh muscle and statistically significant between two variables in control group.

\begin{tabular}{lcc}
\multicolumn{1}{c}{ Indicator } & $\begin{array}{c}\text { Omega-3 polyunsaturated fatty } \\
\text { acids }\end{array}$ & $\begin{array}{c}\text { Omega-6 polyunsaturated fatty } \\
\text { acids }\end{array}$ \\
\hline Polyunsaturated fatty acids & $0.82, p>0.05$ & $1.00, p<0.001$ \\
Omega-3 polyunsaturated fatty acids & & $0.73, p>0.05$ \\
\hline
\end{tabular}

Note: Numeric value - correlation coefficient $\left(\mathrm{r}_{\mathrm{xy}}\right)$ between variables, $p>0.05$ : no statistically significant difference between two variables, $p<0.001$ : statistically significant difference between two variables

Table 5 Correlation relation between polyunsaturated, omega-3 a omega-6 polyunsaturated fatty acids in fat of broiler chicken thigh muscle and statistically significant between two variables in experimental group with supplement of eugenol, nerolidol and piperine.

\begin{tabular}{lcc}
\multicolumn{1}{c}{ Indicator } & $\begin{array}{c}\text { Omega-3 polyunsaturated fatty } \\
\text { acids }\end{array}$ & $\begin{array}{c}\text { Omega-6 polyunsaturated fatty } \\
\text { acids }\end{array}$ \\
\hline Polyunsaturated fatty acids & $0.29, p>0.05$ & $0.98, p<0.01$ \\
Omega-3 polyunsaturated fatty acids & & $0.28, p>0.05$ \\
\hline
\end{tabular}

Note: Numeric value - correlation coefficient $\left(\mathrm{r}_{\mathrm{xy}}\right)$ between variables, $p>0.05$ : no statistically significant difference between two variables, $p<0.001$ : statistically significant difference between two variables. 
Table 6 Mean values for ratio between omega-3 and omega- 6 polyunsaturated fatty acids in fat of broiler chicken thigh muscle.

\begin{tabular}{|c|c|c|c|c|c|}
\hline \multirow[t]{2}{*}{ Group } & \multicolumn{2}{|c|}{ Ratio } & \multirow[b]{2}{*}{$S D$} & \multirow[b]{2}{*}{$c_{v}, \%$} & \multirow[b]{2}{*}{ t-test } \\
\hline & $\begin{array}{c}\text { Omega-3 } \\
\text { polyunsaturated } \\
\text { fatty acids, } n=6 \\
\end{array}$ & $\begin{array}{c}\text { omega-6 } \\
\text { polyunsaturated } \\
\text { fatty acids, } n=6\end{array}$ & & & \\
\hline \multirow{2}{*}{$\begin{array}{l}\text { Control } \\
\text { Experimental with supplement of } \\
\text { eugenol, nerolidol and piperine }\end{array}$} & 1 & 16.78 & 2.91 & 17.34 & \multirow[b]{2}{*}{$p<0.05$} \\
\hline & 1 & 14.65 & 3.72 & 25.39 & \\
\hline
\end{tabular}

Note: $\mathrm{n}$ - multiplicity.

\section{Share of omega-3 and omega-6 polyunsaturated fatty acids from total fatty acids in fat of broiler chicken thigh muscle}

Mean values and statistical analysis for share of omega-3 and omega- 6 polyunsaturated fatty acids from total fatty acids in fat of broiler chicken thigh muscle shows Table 3. Omega-3 polyunsaturated fatty acids content was reached $0.54 \%$ from total fatty acids in fat of broiler chicken thigh muscle in experimental group with supplement of eugenol, nerolidol and piperine and $0.58 \%$ in control group. These values are comparable without statistically significant $(p>0.05)$. A slightly larger difference was found in the omega-6 polyunsaturated fatty acid content between the control group and the experimental group with the supplement of eugenol, nerolidol and piperine, which was not statistically significant $(p>0.05)$. In recent years, there has been interest in the role of poultry meat as a dietary source of long chain omega-3 polyunsaturated fatty acids, including alpha-linolenic acid (ALA, 18:3), eicosapentaenoic acid (EPA, 20:3) and docosahexaenoic acid (DHA, 22:6) (Dalziel, Kliem and Givens, 2015). Observational studies randomized clinical trials, and in vivo experimental studies have established the likely magnitude and dose-response of benefits e.g. of fish and fish oil consumption as prevention of coronary heart disease and Sudden cardiac death as well as the effects of omega-3 fatty acids on a wide range of cardiovascular risk factors. The molecular mechanisms underlying these benefits are not well established, and continued experimental investigation is needed to clarify the effects of omega-3 fatty acids on different tissues on ion channels, other transmembrane protein receptors and lipid rafts, endoplasmic reticulum and mitochondrial function, and cytosolic nuclear receptors (Mozaffarian, 2008).

\section{Correlation relation between polyunsaturated, omega-3 and omega-6 polyunsaturated fatty acids in fat of broiler chicken thigh muscle}

Correlation relation between polyunsaturated, omega-3 and omega- 6 polyunsaturated fatty acids in fat of broiler chicken thigh muscle and its statistically significant between two variables in control group shows Table 4 and experimental group with supplement of eugenol, nerolidol and piperine shows Table 5. Near-perfect correlation relation was found between total polyunsaturated and omega-6 polyunsaturated fatty acids as well in the experimental group with supplement of eugenol, nerolidol and piperine, and control group. This correlation was linear, positive and statistically significant $(p<0.01$, $p<0.001)$.

\section{Ratio between omega-3 and omega- 6 polyunsaturated fatty acids in fat of broiler chicken thigh muscle}

Mean values of ratio between omega-3 and omega- 6 polyunsaturated fatty acids in fat of broiler chicken thigh muscle shows Table 6 . Ratio between omega-3 and omega-6 polyunsaturated fatty acids was statistically significant $(p<0.05)$ closer in experimental group with supplement of eugenol, nerolidol and piperine 1:14.65 opposite ratio $1: 16.78$ between omega-3 and omega- 6 polyunsaturated fatty acids in control group. Adequate intake of omega-3 polyunsaturated fatty acids, a balanced ratio between omega-3 polyunsaturated fatty acids and omega-6 polyunsaturated fatty acids, even a proper ratio between polyunsaturated fatty acids and saturated fatty acids, may reduce the risk of life-style diseases such as coronary artery disease, hypertension, diabetes, and inflammatory and immune disorders (Zhou et al., 2012). There is evidence suggesting that saturated fatty acids have negative consequences on human health whereas polyunsaturated fatty acids have beneficial effects (Gibbs, Rymer and Givens, 2013); polyunsaturated fatty acids should constitute $7 \%$ of total energy consumed (Soriano-Santos, 2010).

\section{CONCLUSION}

Based on the statistical evaluation of our experimental results with the Ross 308 broiler chickens, we can conclude that by the effect of the biologically active substances of eugenol, nerolidol and piperine as a supplement in feed mixtures, compared to the control group, was achieved:

a) comparable fat profile in the thigh muscle, showing no statistically significant difference $(p>0.05)$,in addition to the correlation between polyunsaturated and omega- 6 polyunsaturated fatty acids, which was statistically significant in control $(p<0.001)$ and experimental groups with eugenol, nerolidol, piperine $(p<0.01)$,

b) statistically significant $(p<0.05)$ and closer relationship between omega-3 and omega-6 polyunsaturated fatty acids.

\section{REFERENCES}

Abdulazeez, M. A., Sani, I., James, B. D., Abdullahi, A. S. 2016. Black Pepper (Piper nigrum L.) Oils. Chapter 31. In PREEDY V. R. Essential Oils in Food Preservation, Flavor and Safety. Cambridge, United States : Academic Press, p. 277-285. ISBN 978-0-12-416641-7. https://doi.org/10.1016/B978-0-12-416641-7.00031-6

Afify, A. E., El-Beltagi, H. S., Aly, A. A., El-Ansary, A. E. 2012. Antioxidant enzyme activities and lipid 
peroxidation as biomarker for potato tuber stored by two essential oils from caraway and clove and its main component carvone and eugenol. Asian Pacific Journal of Tropical Biomedicine, vol. 2, no. 2, p. 772-780. https://doi.org/10.1016/S2221-1691(12)60312-8

Angelovič, M., Jablonický, J., Tkáč, Z., Angelovič, M. 2015. Oxidative Stability of Fatty Acid Alkyl Esters: a review. Potravinarstvo, vol. 9, no. 1, p. 417-426. https://doi.org/10.5219/500

AOAC 983.18. Meat and Meat Products - Preparation of Test Sample Procedure.

Blažeković, B., Yang, W., Wang, Y., Li, CH., Kindl, M., Pepeljnjak, S., Vladimir-Knežević, S. 2018. Chemical composition, antimicrobial and antioxidant activities of essential oils of Lavandula $\times$ intermedia 'Budrovka' and $L$. angustifolia cultivated in Croatia. Industrial Crops and Products, vol. 123, p. 173-182. https://doi.org/10.1016/j.indcrop.2018.06.041

Chia-Wen, L., Chia-Wen, Y., Sung-Chuan, W., KuangHway, Y. 2009. DPPH free-radical scavenging activity, total phenolic contents and chemical composition analysis of fourty-two kinds of essential oils. Journal Food Drug Analysis, vol. 17, no. 5, p. 386-395.

Cohen, J. 1988. Statistical power analysis for the behavioral sciences, $2^{\text {nd }}$ ed. New York, USA : Academic Press, 590 p. ISBN-13 978-0805802832.

Council Directive 2007/43/EC of 28 June 2007 laying down minimum rules for the protection of chickens kept for meat production.

Dalziel, C. J., Kliem, K. E., Givens, D. I. 2015. Fat and fatty acid composition of cooked meat from UK retail chickens labelled as from organic and non-organic production systems. Food Chemistry, vol. 179, p. 103-108. https://doi.org/10.1016/j.foodchem.2015.01.118

Dănilă, E., Moldovan, Z., Popa, M., Chifiriuc, M. C., Kaya, A. D., Kaya, M. A. 2018. Chemical composition, antimicrobial and antibiofilm efficacy of $C$. limon and $L$. angustifolia EOs and of their mixtures against Staphylococcus epidermidis clinical strains. Industrial Crops and Products, vol. 122, p. 483-492. https://doi.org/10.1016/j.indcrop.2018.06.019

De Smet, S., Raes, K., Demeyer, D. 2004. Meat fatty acid composi-tion as affected by fatness and genetic factors, a review. Animal Research, vol. 53, p. 81-98. https://doi.org/10.1051/animres:2004003

Ezawa, T., Inoue, Y., Tunvichien, S., Suzuki, R., Kanamoto, I. 2017. Changes in the Physicochemical Properties of Piperine/ $\beta$-Cyclodextrin due to the Formation of Inclusion Complexes. International Journal of Medicinal Chemistry, vol. 2016, p. 1-10. https://doi.org/10.1155/2016/8723139

Gibbs, R. A., Rymer, C., Givens, D. I. 2013. Fatty acid composition of cooked chicken meat and chicken meat products as influenced by price range at retail. Food Chemistry, vol. 2-3, no. 138, p. 1749-1756. https://doi.org/10.1016/j.foodchem.2012.11.002

Gorgani, L., Mohammadi, M., Najafpour, G. D., Nikzad, M. 2017. Piperine - the Bioactive Compound of Black Pepper: From Isolation to Medicinal Formulations. Comprehensive Reviews in Food Science and Food Safety, vol. 16, no. 1, p. 124-140. https://doi.org/10.1111/1541-4337.12246

Hanamanthagouda, M. S., Kakkalameli, S. B., Naik, P. M., Nagella, P., Seetharamareddy, H. R., Murthy, H. N. 2010. Essential oils of Lavandula bipinnata and their antimicrobial activities. Food Chemistry, vol. 118, no. 3, p. 836-839. https://doi.org/10.1016/j.foodchem.2009.05.032
Hui, L., He, L., Huan, L., Xiao, L., Zhou, A. G. 2010. Chemical composition of lavender essential oil and its antioxidant activity and inhibition against rhinitisrelated bacteria. African Journal of Microbiology Research, vol. 4, no. 4, p. 309-313.

Kardum, N., Glibetic, M. 2018. Polyphenols and their Interactions with other Dietary Compounds: Implications for Human Health. Advances in Food and Nutrition Research, vol. 84 , p.

103-144.

https://doi.org/10.1016/bs.afnr.2017.12.001

Lee, M. K., Lim, S., Song, J. A., Kim, M. E., Hur, M. H. 2017. The effects of aromatherapy essential oil inhalation on stress, sleep quality and immunity in healthy adults: Randomized controlled trial. European Journal of Integrative Medicine, vol. 12, no. 6, p. 79-86. https://doi.org/10.1016/j.eujim.2017.04.009

Mbaveng, A. T., Kuete, V. 2017. Chapter 29 - Syzygium aromaticum. In Kuete, V. Medicinal Spices and Vegetables from Africa. Cambridge, United States : Academic Press, p. 611-625 ISBN 978-0-12-809286-6.

https://doi.org/10.1016/B978-0-12-809286-6.00029-7

Mensink, R. P., Katan, M. B. 1992. Effect of dietary fatty acids onserum lipids and lipoproteins, a meta-analysis of 27 trials. Arteriosclerosis and thrombosis, vol. 12, p. 911-919. https://doi.org/10.1161/01.ATV.12.8.911

Mgbeahuruike, E. E., Yrjönen, T., Vuorela, H., Holm, Y. 2017. Bioactive compounds from medicinal plants: Focus on Piper species. South African Journal of Botany, vol. 112, no. 9, p. 54-69. https://doi.org/10.1016/j.sajb.2017.05.007

Mhaske, D. B., Sreedharan, S., Mahadik, K. R. 2018. Role of Piperine as an Effective Bioenhancer in Drug Absorption. Pharmaceutica Analytica Acta, vol. 9, no. 7, p. 591. https://doi.org/10.4172/2153-2435.1000591

Mozaffarian, D. 2008. Fish and n-3 fatty acids for the prevention of fatal coronary heart disease and sudden cardiac death. American Journal of Clinical Nutrition, vol. 87, no. 6, p. 1991S-1996S. https://doi.org/10.1093/ajcn/87.6.1991S

Pereira, I., Severino, P., Santos, A. C., Silva, A. M., Souto, E. B. 2018. Linalool bioactive properties and potential applicability in drug delivery systems. Colloids and Surfaces $B$ : Biointerfaces, vol. 171, no. 11, p. 566-578. https://doi.org/10.1016/j.colsurfb.2018.08.001

SAS, 2008. 9.3 Enhanced Logging Facilities. [Computer software].Cary, NC : SAS Institute.

Siriwardhana, N., Nishan, S., Kalupahana, S., Naima Moustaid-Moussa, N. 2012. Health benefits of n-3 polyunsatu-rated fatty acids: eicosapentaenoic acid and docosahexaenoicacid. Advances in Food and Nutritional Research, vol. 65, p. 211-222. https://doi.org/10.1016/B9780-12-416003-3.00013-5

Soriano-Santos, J. 2010. Chemical Composition and Nutritional Content of Raw Poultry Meat. In GuerreroLegarreta, I. Handbook of Poultry Science and Technology. Hoboken, New Jersey : John Wiley \& Sons. p. 467-491. ISBN

978-0-470-18552-0 https://doi.org/10.1002/9780470504451.ch25

Tkáčová, J., Angelovičová, M., Hašč́k, P., Bobko, M. 2015. Oxidative stability of chicken meat during storage influenced by the feeding of alfalfa meal. Potravinarstvo, vol. 9, no. 1, p. 106-111. https://doi.org/10.5219/444

Vannice, G., Rasmussen, H. 2014. Position of the Academy of Nutrition and Dietetics:Dietary Fatty Acids for Healthy Adults. Journal of the Academy of Nutrition and Dietetics, vol. 114, $136-153$. https://doi.org/10.1016/j.jand.2013.11.001 
Viuda-Martos, M., Mohamady, M. A., Fernández-López, J., Abd Elrazik, K. A., Omer, E. A., Pérez-Alvarez, J. A., Sendra, E. 2011. In vitro antioxidant and antibacterial activities of essentials oils obtained from Egyptian aromatic plants. Food Control, vol. 22, no. 11, p. 1715-1722. https://doi.org/10.1016/j.foodcont.2011.04.003

Zhou, L. J., Wu, H., Li, J. T., Wang, Z. Y., Zhang, L. Y. 2012. Determination of fatty acids in broiler breast meat by near-infrared reflectance spectroscopy. Meat Science, vol. 90, no. 3 , p. 658-664. https://doi.org/10.1016/j.meatsci.2011.10.010

\section{Acknowledgments: \\ This work was supported by project Building Research Centre Agrobiotech No. 26220220180.}

\section{Contact address:}

*Mária Angelovičová, Slovak University of Agriculture, Faculty of Biotechnology and Food Sciences, Department of Hygiene and Food Safety, Trieda A. Hlinku 2, 94976 Nitra, Slovakia, Tel.: +4216415805, E-mail: maria.angelovicova@uniag.sk

Michaela Klimentova, Slovak University of Agriculture, Faculty of Biotechnology and Food Sciences, Department of Hygiene and Food Safety, Trieda A. Hlinku 2, 94976 Nitra, Slovakia, Tel.: +4216415805, E-mail: supermys0@gmail.com

Marek Angelovič, Slovak University of Agriculture, Faculty of Engineering, Department of Machines and production systems, Trieda A. Hlinku 2, 94976 Nitra, Slovakia, Tel.: $\quad+4216414363, \quad$ E-mail: marek.angelovic@uniag.sk

Corresponding author: * 